\title{
Assessment and improvement of indoor environmental quality in a primary school
}

\author{
ORHAN EKREN ${ }^{1}$, ZIYA HAKTAN KARADENIZ ${ }^{2}$, IBRAHIM ATMACA ${ }^{3}$, TUGBA UGRANLI-CICEK ${ }^{4,5}$, \\ SAIT C. SOFUOGLU ${ }^{4,5, *}$, and MACIT TOKSOY ${ }^{6}$ \\ ${ }^{1}$ Ege University, Solar Energy Institute, Izmir, Turkey \\ ${ }^{2}$ Department of Mechanical Engineering, İzmir Katip Celebi University, Cigli, Izmir, Turkey \\ ${ }^{3}$ Department of Mechanical Engineering, Akdeniz University, Antalya, Turkey \\ ${ }^{4}$ Department of Chemical Engineering, Izmir Institute of Technology Gulbahce, Urla, Izmir 35430, Turkey \\ ${ }^{5}$ Department of Environmental Engineering, Izmir Institute of Technology, Izmir, Turkey \\ ${ }^{6}$ ENEKO, Cigli, Izmir, Turkey
}

\begin{abstract}
This study reports levels of indoor environmental quality variables before and after installation of heat recovery ventilation in a primary school located in an urban area in Izmir, Turkey. $\mathrm{A} \mathrm{CO}_{2}$-based modeling was performed to determine the required flow rates that would comply with an international ventilation standard, followed by computational fluid dynamics modeling for best airflow distribution in a classroom. Temperature, $\mathrm{CO}_{2}, \mathrm{PM}_{2.5}$, and total volatile organic compounds were found at undesired levels, among which relative humidity, $\mathrm{CO}_{2}$, and $\mathrm{PM}_{2.5}$ were improved after the intervention. Reductions in the mean and maximum concentrations were $29 \%$ and $68 \%$ for $\mathrm{CO}_{2}$ and $29 \%$ and $46 \%$ for $\mathrm{PM}_{2.5}$. This intervention study was a part of the city-wide main project that aimed to increase awareness of the students and their families, teachers, and staff regarding importance of indoor environmental quality in both at school and home due to its possible effects on children's health and academic performance, one of the major challenges of today's societies all around the globe.
\end{abstract}

\section{Introduction}

School buildings, including daycares and kindergartens, are one of the most important indoor environmental quality (IEQ) issues today because (1) children spend the most of their time in these buildings second to home; (2) high population density, poor ventilation, lack of maintenance, and unsatisfactory cleaning are common, and there are unique sources of pollution leading to very high pollutant concentrations compared to outdoors (Daisey et al. 2003; de Gennaro et al. 2014; Mendell and Heath 2005); and (3) children are sensitive and susceptible to the environmental effects not only because they are still growing (Faustman et al. 2000) but also due to their physical activity and behavior (Annesi-Maesano et al. 2013). Outdoor air is also a source through ventilation and

Received April 22, 2016; accepted October 3, 2016

Orhan Ekren, PhD, Member ASHRAE, is an Associate Professor. Ziya Haktan Karadeniz, PhD, is an Assistant Professor. Ibrahim Atmaca, PhD, is an Associate Professor. Tugba UgranliÇiçek, MSc, is a Graduate Research Assistant. Sait C. Sofuoglu, PhD, is a Professor. Macit Toksoy, PhD, Member ASHRAE, is an R\&D Supervisor and a Professor Emeritus.

${ }^{*}$ Corresponding author e-mail: cemilsofuoglu@iyte.edu.tr Color versions of one or more of the figures in the article can be found online at www.tandfonline.com/uhvc. penetration for pollutants which generally have lower indoor source strengths compared to those of outdoors (de Gennaro et al. 2014; Mendell and Heath 2005).

Inorganic gaseous contaminants such as $\mathrm{CO}, \mathrm{NO}_{2}, \mathrm{O}_{3}$, organic gaseous pollutants such as volatile organic compounds (VOCs), bioaerosols, particulate matter (PM), and semi-VOCs that partition between the gaseous and particulate phases are some of the main groups of indoor air pollutants in schools. Ultrafine particles (UFP, particles with diameters $<100 \mathrm{~nm}$ ) are reported to be an important PM size group with higher exposure potential due to deep penetration into the lungs and large surface area for biological interactions, source of which are mainly outdoor air (traffic and new particle formation) for schools with no cooking activities (Fuoco et al. 2015). While $\mathrm{CO}_{2}$ has been considered as an indicator of air exchange, a recent study showed that it may be an indoor air pollutant (Satish et al. 2012).

In addition to acute symptoms such as headache, dizziness, tiredness, eyes-nose-throat-skin irritation, and wheezing, indoor air pollution have been associated with allergic disorders, such as allergic rhinitis, allergic sensitization, atopic dermatitis, and allergic asthma, and diseases such as chronic obstructive pulmonary disease (Annesi-Maesano et al. 2013). Furthermore, academic performance, school absenteeism, scoring in standardized tests, decision making, memory, concentration, error rate have been associated with IEQ and ventilation (Annesi-Maesano et al. 2013; Bakó-Biró et al. 
2012; Haverinen-Shaughnessy et al. 2015; Mendell and Heath 2005; Satish et al. 2012; Shaughnessy et al. 2006; Shendell et al. 2004; Stafford 2015; Twardella et al. 2012).

Consequently, provision of sufficient fresh air through ventilation is critical to sustain school IEQ for the health and success of children. However, it is difficult to use natural ventilation because of number, variety, and strength of pollution sources, and population density. Therefore, mechanical ventilation has commonly been suggested and applied as the solution, which requires pollution control measures for those buildings located in polluted areas such as metropoles and industrial areas. Due to financial restrictions that majority of schools face, heat recovery ventilation (HRV) is considered appropriate for energy and operating cost savings, which may also result in mechanical ventilation becoming source of contamination due to lack of maintenance and cleaning. Nonetheless, occupant behavior is a significant factor that may impact IEQ. Hence, IEQ management requires awareness and involvement of students, teachers, and school management.

Studies conducted in some European countries, the United States, Australia, and countries with specific climatic conditions such as Singapore produced information regarding the significance of IEQ in relation to children's health and academic performance (e.g., cited in Daisey et al. 2003; Mendell and Heath 2005; Wargocki et al. 2002) propagated interest all around the globe where the significance of IEQ have started to be recognized (e.g., Elbayoumi et al. 2013; Halek et al. 2013; Jovanović et al. 2014; Mainka et al. 2015; Mohamad et al. 2016; Sohn et al. 2009) including Turkey (Babayiğit et al. 2014; Demirel et al. 2014; Ekmekcioglu and Keskin 2007; Mentese et al. 2012; Sofuoglu et al. 2010, 2011). In such places, schools are naturally ventilated, and energy-conscious intervention for existing schools will be the main task that should be guided by the scientific studies (such as Norback et al. 2011; Rosbach et al. 2013; Wargocki and Da Silva 2015). Thus, it is crucial for those studies to have a holistic approach.

This study aimed to conduct a pilot study to investigate application of HRV to provide a healthy classroom indoor environment for pupils of an elementary school in a polluted urban environment. IEQ (thermal comfort and indoor air quality [IAQ]) was measured before and after installation of the mechanical ventilation, for which flow rate was estimated by modeling $\mathrm{CO}_{2}$ in a classroom to design a system that could comply with a selected international standard. Efforts of raising awareness were included (guidebooks were written and distributed to children and teachers/management, seminars were given, and a website, www.iccevrekalitesi.net, was constructed) in the scope of the project but its effects were not measured.

\section{Material and methods}

\section{Building location and characteristics}

The selected school (Nihat Gündüz Ortaokulu) is located in Işıkkent area in Izmir, Turkey, where there are some industrial facilities such as two cement plants at distances of
2.2 and $3.0 \mathrm{~km}$, and two beer plants 0.7 and $1.0 \mathrm{~km}$ away, a household and personal care products plant $(1.3 \mathrm{~km})$, many small and medium sized enterprises (SMEs), and a highway and intersection of major roadways (Figure $\mathrm{S} 1$ in supporting information [SI]). It houses both elementary and secondary grade levels. Some important information about the school are as follows: A three-floor building with a basement, 16 classrooms, 1 kindergarten, 350 students, 25 teachers, classes from 0840 to 1520 weekdays with 40 min periods, 10 min breaks, and a $1 \mathrm{~h}$ lunch break.

A classroom of 30 students, which is located on the ground floor, was selected for IAQ and thermal comfort monitoring, and installation of HRV mechanical ventilation unit. The classroom $(\mathrm{L} \times \mathrm{W} \times \mathrm{H}$ of $630 \times 630 \times 290 \mathrm{~cm})$ was occupied by the 4 th graders. Monitoring devices were placed in a casing in the middle of the classroom (SI, Figure S2). Classes of the 4th graders started at 0840 and ended at 1420 with $10 \mathrm{~min}$ breaks between 40 min periods. A lunch break of $1 \mathrm{~h}$ was given after the 4th period.

\section{IAQ monitoring}

IAQ monitoring device (Quest EVM-7) was capable of simultaneously monitoring $\mathrm{CO}_{2}, \mathrm{NO}_{2}, \mathrm{PM}_{10}$, and total volatile organic compounds (TVOC). It was placed at the height of $1.1 \mathrm{~m}$ at the breathing level of the students (SI, Figure S2). IAQ monitoring was conducted in the classroom for six, 1-week periods in October 2014-January 2015 period before intervention, and for two weeks after intervention. Before intervention, monitoring was also conducted during the weekend of the first week. In addition, two scenarios were run: (1) regular operation in which students left the classroom as they pleased during the breaks; and (2) all students were required to open all the windows and leave the classroom. The device was run daytime starting $20 \mathrm{~min}$. before the 1 st period to $2.5 \mathrm{~h}$ after the end of the last period. Monitoring was also conducted nighttime for at least $4 \mathrm{~h}$.

The monitoring device measures $\mathrm{PM}_{10}$ concentrations by a $90^{\circ}$ optical light emitting photometer, and reports in $\mu \mathrm{g} / \mathrm{m}^{3}$. Calibration of the device for PM was based on Arizona Street Dust by the manufacturer, so a correction factor was required for reliable results in a specific indoor environment. This correction factor was determined by conducting a preliminary sampling campaign that monitored the PM concentrations and collected the particles on a filter placed into the internal filter holder of the device. Comparison of the mass and counter based concentrations resulted in a factor value of two. TVOC concentrations are measured with a photo ionization detector (PID) in ppb units. $\mathrm{CO}_{2}$ and $\mathrm{NO}_{2}$ concentrations are measured in ppm units with a nondispersive infrared (NDIR) sensor. These detectors were calibrated according to manufacturer described methods. Concentrations were measured at $30 \mathrm{~s}$ intervals, and reported as 5-min averages.

\section{Thermal comfort assessment}

Thermal comfort conditions of students were assessed using both objective measurements and subjective surveys. 
Temperature and relative humidity $(\mathrm{RH})$ were measured every 10 min with Hobo U12 devices at the ankle, waist, and head heights for a seated child, which are $0.1,0.6$, and $1.1 \mathrm{~m}$, respectively, according to ASHRAE Standard 55 (2013) in the pilot classroom. Like IAQ monitoring, thermal comfort assessment was conducted in the classroom for six, 1-week periods in October 2014-January 2015 before intervention, and for 2 weeks in February 2015 after intervention. It was observed that students wore warm enough clothes, therefore, assessments were made by accepting the $20^{\circ} \mathrm{C}-24^{\circ} \mathrm{C}$ temperature range as the comfort range as recommended in ASHRAE Standard 55 (2013). In addition, subjective assessment was made by applying a thermal comfort survey (Teli et al. 2012) to the students of the classroom. A 7-point scale predicted mean vote (PMV) index was used for the survey. In this scale, -3 is cold, -2 is cool, -1 is slightly cool, 0 is neutral, +1 is slightly warm, +2 is warm, and +3 is hot. A school-wide subjective inquiry was performed in a total of 14 different classrooms during the months of December and January, whereas after intervention it was administered in two classrooms for 3 days in February, where the mechanical ventilation was installed. Days with very low outside temperatures were carefully selected for the application of the survey in order to assess the most negative thermal comfort conditions for the school. The same questions were asked in different ways to achieve cross-examination and the most accurate results. The students were asked about their clothing to identify unusual responses due to clothing, which were then eliminated. Responses to cross-examination questions were compared, and inconsistent answers were eliminated.

\section{Mechanical ventilation design}

\section{$\mathrm{CO}_{2}$ modeling for determination of ventilation rate}

Ianniella (2011) compared ventilation standards applicable for school buildings in the European Union (EU), Finland, France, the Netherlands, Portugal, the United Kingdom, and the United States. These standards recommend minimum fresh air per person and/or per unit area, and maximum $\mathrm{CO}_{2}$ concentration individually or in combination. Both types are considered in detail in Building Bulletin 101 of the United Kingdom requiring a minimum of $3 \mathrm{~L} / \mathrm{s} / \mathrm{p}$ which can be increased to $8 \mathrm{~L} / \mathrm{s} / \mathrm{p}$ when needed, and keeping $\mathrm{CO}_{2}$ concentration (1) below $1500 \mathrm{ppm}$ for periods of without a long break; (2) below 5000 ppm during the school day; and (3) $\mathrm{CO}_{2}$ concentration can be reduced below $1000 \mathrm{ppm}$ at any time (BDE 2006). Therefore, this standard was selected to comply with. As a result, indoor air $\mathrm{CO}_{2}$ concentration in the pilot classroom was modeled to determine the design flow rate for the mechanical ventilation to be installed. $\mathrm{A} \mathrm{CO}_{2}$ mass balance (Equation 1) as it was recently used by Kalema and Viot (2014) was employed to model the concentrations for different flow rates that would ascertain compliance with the standard. Equation 1 can be solved for constant flow rate, inlet concentration, and $\mathrm{CO}_{2}$ production rate (Equation 3) for a given time period as in Equation 2.

$$
V \frac{d C}{d t}=G(t)+Q\left(C_{\text {inlet }}-C(t)\right)
$$

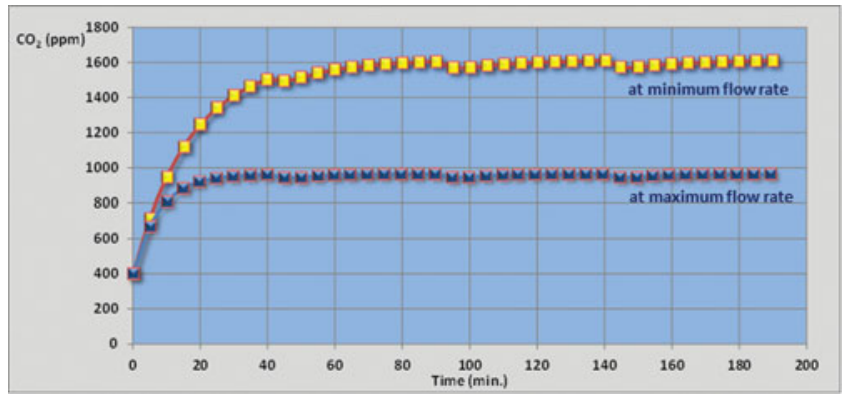

Fig. 1. Modeled pilot classroom $\mathrm{CO}_{2}$ concentrations at minimum and maximum flow rates.

$$
\begin{gathered}
C(t)-C_{\text {inlet }}+\frac{G(t)}{Q}+\left[C(0)-C_{\text {inlet }}-\frac{G(t)}{Q}\right] e^{-n t} \\
G=R Q \frac{0.00276 A_{D u} M}{0.23 R Q+0.77} \\
A_{D u}-0.202 W_{b}^{0.425} H_{b}^{0.725}
\end{gathered}
$$

where $Q$ is flow rate, $V$ is volume, $n=Q / V$ is the air change rate, $C(0)$ and $C(\mathrm{t})$ are indoor air concentration at time $t=$ 0 and $t=\mathrm{t}, G$ is $\mathrm{CO}_{2}$ production rate, RQ is the respiratory quotient assumed as $0.83, M$ is metabolic rate assumed as 1.2 for sedentary activity in schools, $A_{D u}$ is human body surface area estimated using DuBois equation (Equation 4), where $W$ and $H$ are body weight and height. The following values were used in the model: classroom dimensions as $6.3 \times 6.3 \times 2.9(\mathrm{~h})$ $\mathrm{m}$, number of people as 31 (30 students + a teacher) during the classes and 30 students during the breaks, student body weight, height, and metabolic rate as $32.4 \mathrm{~kg}, 1.38 \mathrm{~m}$, and 1.2 met, respectively, class and break lengths as 40 min periods and 10 min breaks, and number of periods without a long break as four classes before the $1 \mathrm{~h}$ lunch break.

The modeling has shown that $\mathrm{CO}_{2}$ concentrations are kept below the levels indicated in the standard (see Figure 1) when the flow rate is $3.7 \mathrm{~L} / \mathrm{s} / \mathrm{p}\left(413 \mathrm{~m}^{3} / \mathrm{h}\right)$ at the minimum and $8.0 \mathrm{~L} / \mathrm{s} / \mathrm{p}\left(893 \mathrm{~m}^{3} / \mathrm{h}\right)$ at the maximum, even when everybody (except for the teacher) remain in the classroom during the 10 min breaks.

\section{Computational fluid dynamics (CFD) modeling}

Three-dimensional (3D) simulations has given us the opportunity to investigate every case in detail and find the most proper solution for ventilation. Unlike the simplified 3D simulation predecessors (Mizuno and Warfield 1992; Murakami, 1997; Murakami et al. 1998, 2000), one of the most detailed and earliest 3D investigations about ventilation of an occupied space in the literature were proposed by Abanto et al. (2004). The results of these studies showed that 3D modeling is a very important tool for obtaining the proper ventilation design. 3D IAQ simulations for classrooms are also proposed in the literature, such as two recent studies on energy efficiency and classroom air environment (Wang et al. 2014a, 2014b). They represented the occupants as rectangular prisms in their 

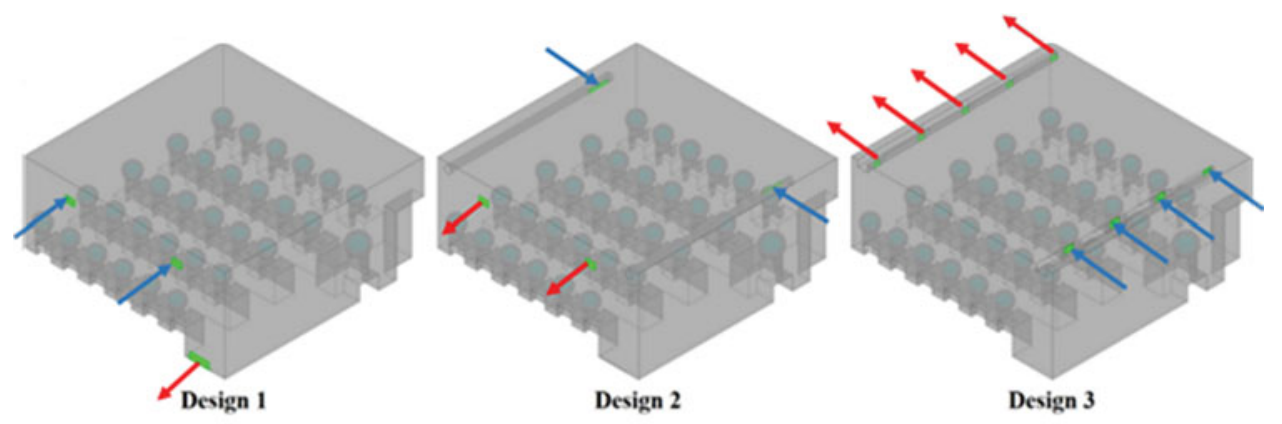

Fig. 2. Investigated ventilation scenarios.

model and reported the temperature, velocity, and $\mathrm{CO}_{2}$ concentration distributions to analyze the ventilation effectiveness. Kosonen and Mustokallio (2015) compared different mechanical air distribution systems via 3D computer simulations. They used cylinders to represent the occupants in the classroom and visualized the velocity distribution inside the classroom.

CFD modeling was also used in this study to investigate airflow in the classroom. Three different mechanical ventilation system designs all with heat recovery systems (Figure 2) were compared by 3D CFD analyses to have an efficient ventilation inside the classroom. The first design is the simplest one with two inlets on the wall on the corridor side of the classroom and a transfer grill on the door as an outlet. The second design was more complex with two air inlet grills on two cylindrical inlet ducts which are positioned along opposing upper edges of the classroom parallel to each other. Inlet grills for this design are aligned so as to send air into the classroom inclined from the ceiling. Outlet grills are positioned at the positions of the inlet grills of the first design. The third design is the most detailed one with four inlets and five outlets. Inlets are positioned so as to direct air along the aisles between the desk columns, and outlets are positioned along the opposite edge of the inlet duct aligned with the heads of the students at the end of the each column.

Students and the teacher sit alone on their chairs. The space under the desk is assumed to be covered by the legs of the students so that there is not any flow under the desk. Bodies of the students are modeled as cylinders with oval crosssection, and their heads were modeled as spheres which are partly overlapped with the bodies. Geometric details of the students such as legs, arms, hands, etc., were not modeled for decreasing computational cost. The teacher is also modeled at sitting position in a similar manner. All the remaining devices and furniture were not modeled except for the ventilation ducts and the bookshelf. Dimensions of the model are given in Figure 3.

Although 3D simulations produce incomparably more and high-quality data compared with the two-dimensional (2D) simulations, their results are mostly presented in a $2 \mathrm{D}$ manner in the literature. Different than the previous numerical studies in the literature, spherical air regions were defined around the heads of the occupants to be able to investigate the flow and other IAQ parameters in detail. These spherical air regions are imaginary surfaces inside the air which have no effect on the flow but can be used to visualize and calculate the air quality and comfort indicators around the occupants heads. Therefore, in this study an alternative representation of the results of IAQ calculations for a classroom is presented.

Total fresh air is distributed to the inlet grilles equally. Designs 1 and 2 have two inlet ports that are fed by separated ducts which are located at the outside of the classroom. A $44^{\circ}$ diverging inlet grill with three separated parts $\left(22^{\circ} / 0^{\circ} /-22^{\circ}\right)$ was selected to diffuse the fresh air into the classroom properly in all designs. In addition, vertical directing guides were used to direct the flow downward into the classroom. Therefore, angular orientation of the fresh airflow at the inlets was also defined in the numerical study. There is a suction fan at the outlet port of the heat recovery system for Designs 2 and 3 . The suction effect was included in the numerical study by defining $-20 \mathrm{~Pa}$ relative pressure to the outlets. Exhaust air is free to leave the classroom in Design 1 so the relative pressure

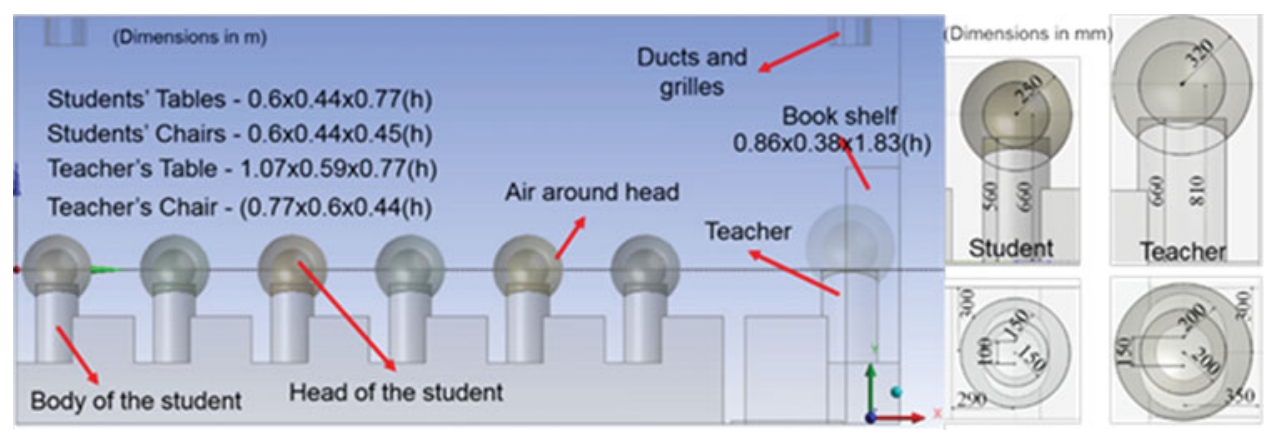

Fig. 3. Details of the investigated geometry. 
(a)

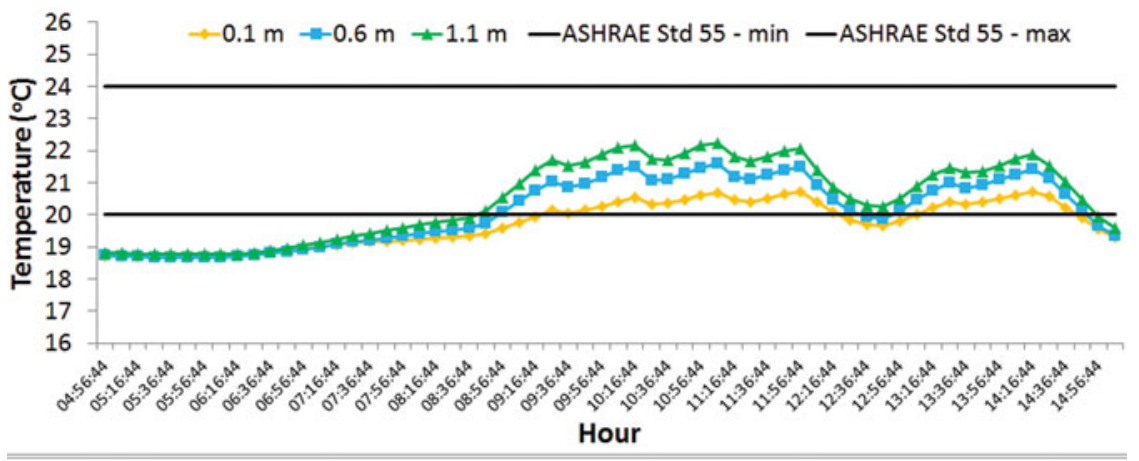

(b)

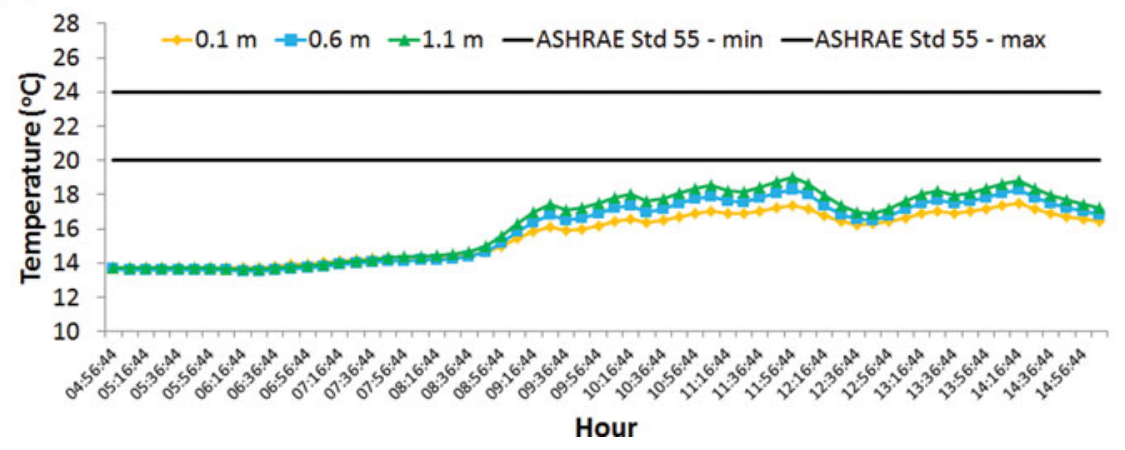

Fig. 4. Diurnal variation in the mean temperature in the pilot classroom in a. December; and b. January.

was $0 \mathrm{~Pa}$ at the outlet. The windows are assumed to be closed and classroom is perfectly insulated to any infiltration. Heat transfer is not modeled and turbulence effects are calculated by using $\mathrm{k}-\varepsilon$ turbulence model.

A commercial software (ANSYS CFX) was used to build the model, define boundary conditions, discretize the solution domain, and solve the corresponding governing equations. Steady Reynolds Averaged Navier Stokes equations were solved with an additional differential equation describing the transport of the scalar "mean age of air" (MAoA). The steady method for calculating MAoA was used due to the proved compromise between accuracy of results and computation time (Chanteloup and Mirade 2009).

To calculate the transport of the scalar " $\phi$ ", one additional convection diffusion equation needs to be solved with the following general form:

$$
\frac{\partial(\rho \phi)}{\partial t}=\nabla \cdot(\rho \vec{V} \phi)+S_{\phi}
$$

where $t$ is time, $\rho$ is the density, $D$ is the kinematic diffusivity of the scalar, $\vec{V}$ is the average velocity that the quantity is moving, $S_{\phi}$ is the source term that defines the source or the sink of the scalar. For steady flows Equation 5 is simplified to:

$$
\nabla \cdot(\rho \vec{V} \phi-\rho D \nabla \phi)=S_{\phi}
$$

The source term is taken as equal to 1 (Bartak et al. 2002; Chanteloup and Mirade 2009; Gan 2000; Hu and Chuah
2003). Kinematic diffusivity of the scalar includes both laminar and turbulent components as:

$$
D=\frac{\mu}{\sigma_{l}}+\frac{\mu_{\mathrm{t}}}{\sigma_{t}}
$$

where $\mu$ and $\mu_{t}$ are the physical and turbulent viscosity, $\sigma_{l}$ and $\sigma_{t}$ are laminar and turbulent Schmidt numbers, respectively. As the solution is turbulent in this case, laminar component will have a poor effect compared to the turbulent one, because turbulent viscosity is higher compared to the laminar viscosity (Chanteloup and Mirade 2009). For turbulent flows, in ANSYS CFX, the turbulent diffusion is included in the solution by default as a consequence of averaging the advection term. Therefore, the kinematic diffusivity is not defined but included in the solution. The boundary conditions for the solution of Equation 2 are a zero value at air inlets and outlets (in case of return flow), as given in the literature (Bartak et al. 2002; Chanteloup and Mirade 2009; Gan 2000; Hu and Chuah 2003).

\section{Results and discussion}

\section{Thermal comfort}

Diurnal variation in the mean temperature values measured in the classroom in December and January are presented in Figure 4. Figure 4a show that in December both of the thermal comfort variables were in the recommended ranges indicated in the figure. Furthermore, it can also be seen from 
Table 1. Subjective thermal comfort survey results for December and January 2014.

\begin{tabular}{|c|c|c|c|c|c|c|}
\hline \multirow[b]{2}{*}{ Classroom } & \multicolumn{3}{|c|}{ December } & \multicolumn{3}{|c|}{ January } \\
\hline & $\mathrm{T}\left({ }^{\circ} \mathrm{C}\right)$ & RH (\%) & Mean PMV & $\mathrm{T}\left({ }^{\circ} \mathrm{C}\right)$ & $\mathrm{RH}(\%)$ & Mean PMV \\
\hline 1 & 21.4 & 46 & +0.05 & 14.0 & 49 & -3.00 \\
\hline 2 & 19.4 & 41 & -1.44 & 15.0 & 50 & -1.28 \\
\hline 3 & 24.0 & 38 & +0.86 & 24.0 & 42 & -0.50 \\
\hline 4 & 21.8 & 36 & -1.63 & 18.0 & 50 & -0.79 \\
\hline 5 & 25.0 & 35 & +0.36 & 15.1 & 53 & -3.00 \\
\hline 6 & 28.0 & 44 & +0.87 & 15.0 & 39 & -2.40 \\
\hline 7 & 24.0 & 44 & +0.59 & 15.8 & 50 & -2.93 \\
\hline 8 & 26.5 & 38 & +1.80 & 18.7 & 52 & -0.55 \\
\hline 9 & 17.5 & 43 & -1.11 & 17.5 & 48 & -1.68 \\
\hline 10 & 23.0 & 44 & +1.00 & 17.3 & 53 & -2.05 \\
\hline 11 & 21.3 & 43 & +0.89 & 16.0 & 43 & -2.76 \\
\hline 12 & 22.6 & 36 & +0.73 & 18.0 & 39 & -0.92 \\
\hline 13 & 19.0 & 48 & -0.27 & 21.2 & 43 & +0.29 \\
\hline 14 & 20.0 & 41 & -0.22 & 21.0 & 31 & -0.79 \\
\hline Mean & 22.4 & 41.2 & +0.18 & 17.6 & 45.9 & -1.66 \\
\hline Standard deviation & 2.95 & 4.04 & +0.97 & 2.85 & 6.51 & 1.10 \\
\hline Minimum & 17.5 & 35 & -1.63 & 14.0 & 31 & -3.00 \\
\hline Maximum & 28.0 & 48 & +1.80 & 24.0 & 53 & +0.29 \\
\hline
\end{tabular}

PMV: predicted mean vote.

Figure 4a that the difference between the ankle and the head levels was not more than $3^{\circ} \mathrm{C}$, which is the recommended value for thermal comfort in the relevant standards. In January on the other hand, the temperature values were never in the comfort zone, and time to time they were much lower than the indicated thermal comfort limit (Figure 4b). RH was within the $50 \%-60 \%$ range in both December and January which influence on thermal comfort is rather limited at these temperature and metabolic activity levels as mentioned in ISO 7730 (2005). Results of the survey performed on December 22, 2014 when the outside temperature was $9.1^{\circ} \mathrm{C}$ are given in Table 1. The temperature in the school varied between $17.5^{\circ} \mathrm{C}$ and $28^{\circ} \mathrm{C}$ depending on the classroom, while $\mathrm{RH}$ varied between $35 \%-48 \%$. The average temperature and $\mathrm{RH}$ values in the school were found as $22.4^{\circ} \mathrm{C}$ and $41.2 \%$, respectively. Under these conditions, the PMV value varied between -1.63 and +1.80 , and the average PMV in the school was +0.18 . As a result, it can be claimed that subjective assessments were in agreement with the temperature and RH measurements performed in the pilot classroom in December. Results of the survey performed on January 8, 2015 when the outside temperature was quite low are also listed in Table 1. Temperature and $\mathrm{RH}$ in the school varied from $14^{\circ} \mathrm{C}$ to $24^{\circ} \mathrm{C}$ and from $31 \%$ to $53 \%$, respectively, among the classrooms. The average temperature and RH values in the school were found as $17.6^{\circ} \mathrm{C}$ and $45.9 \%$, respectively. Under these conditions, the PMV value varied between -3 and +0.29 , while the average PMV in the school was -1.66 . Therefore, subjective assessments were in agreement with the temperature and $\mathrm{RH}$ measurements performed in the pilot classroom in January, which sometimes fall out of the comfort range.

\section{$I A Q$}

The measured $\mathrm{NO}_{2}$ concentrations were generally below the device detection limit of $0.1 \mathrm{ppm}$, therefore, not reported here. Overall average concentrations of the school hours and nighttime were calculated. The mean schooltime concentrations of the 6 weeks for TVOC, $\mathrm{PM}_{2.5}$, and $\mathrm{CO}_{2}$ ranged from 104 to $222 \mathrm{ppb}, 240$ to $666 \mu \mathrm{g} / \mathrm{m}^{3}$, and 958 to $3775 \mathrm{ppm}$, respectively. The respective overall average concentrations ( \pm standard deviation) were calculated as $161 \pm 50 \mathrm{ppb}, 452 \pm$ $177 \mu \mathrm{g} / \mathrm{m}^{3}$, and $2009 \pm 993 \mathrm{ppm}$. The overall averages for the nighttime were lower as $125 \pm 27 \mathrm{ppb}, 402 \pm 208 \mu \mathrm{g} / \mathrm{m}^{3}$, and $539 \pm 177 \mathrm{ppm}$. A higher 24-h maximum $\mathrm{CO}_{2}$ concentration (5900 ppm) was measured in five classrooms in Hong Kong (Lee and Chang 2000). Babayiğit et al. (2014) investigated IAQ in 172 classrooms of 31 primary schools in Ankara, Turkey, from November 2008 to May 2009. Lower average $\mathrm{CO}_{2}$ and similar $\mathrm{NO}_{2}$ levels were measured as $717 \mathrm{ppm}$ and 0.6 ppm, respectively. Fuoco et al. (2015) reported a slightly higher mean $\mathrm{CO}_{2}$ concentration in winter (from November 2014 to March 2015) as $2206 \pm 696 \mathrm{ppm}$, but a similar level $(908 \pm 330 \mathrm{ppm})$ in spring in six naturally ventilated classrooms in Cassino, Italy. Similar average $\mathrm{CO}_{2}$ concentrations (1500-3130 ppm) were measured in the heating season in central Italy but again average concentrations were lower $(<1000 \mathrm{ppm}$, except one classroom $)$ in the nonheating season, claimed to be, due to increasing ventilation rate in five naturally ventilated classrooms (Stabile et al. 2016). A lower mean TVOC concentration was found as $95.3 \mathrm{ppb}\left(219 \mu \mathrm{g} / \mathrm{m}^{3}\right)$ in winter of 2004 in Korea (Yang et al. 2009), and much lower 5-day average $\mathrm{PM}_{2.5}$ concentrations were reported $\left(\sim 14 \mu \mathrm{g} / \mathrm{m}^{3}\right)$ in six French cities (Annesi-Maesano et al. 2012).

The difference between schooltime and nighttime show that while $\mathrm{CO}_{2}$ concentrations reduce significantly (3.7-fold) due to absence of the students as the source, the reduction in TVOC and $\mathrm{PM}_{2.5}$ concentrations were not as sharp (1.3and 1.1-fold, respectively). Weekday-schooltime average concentrations were also about 3-fold higher for $\mathrm{PM}_{2.5}$ and $\mathrm{CO}_{2}$ 

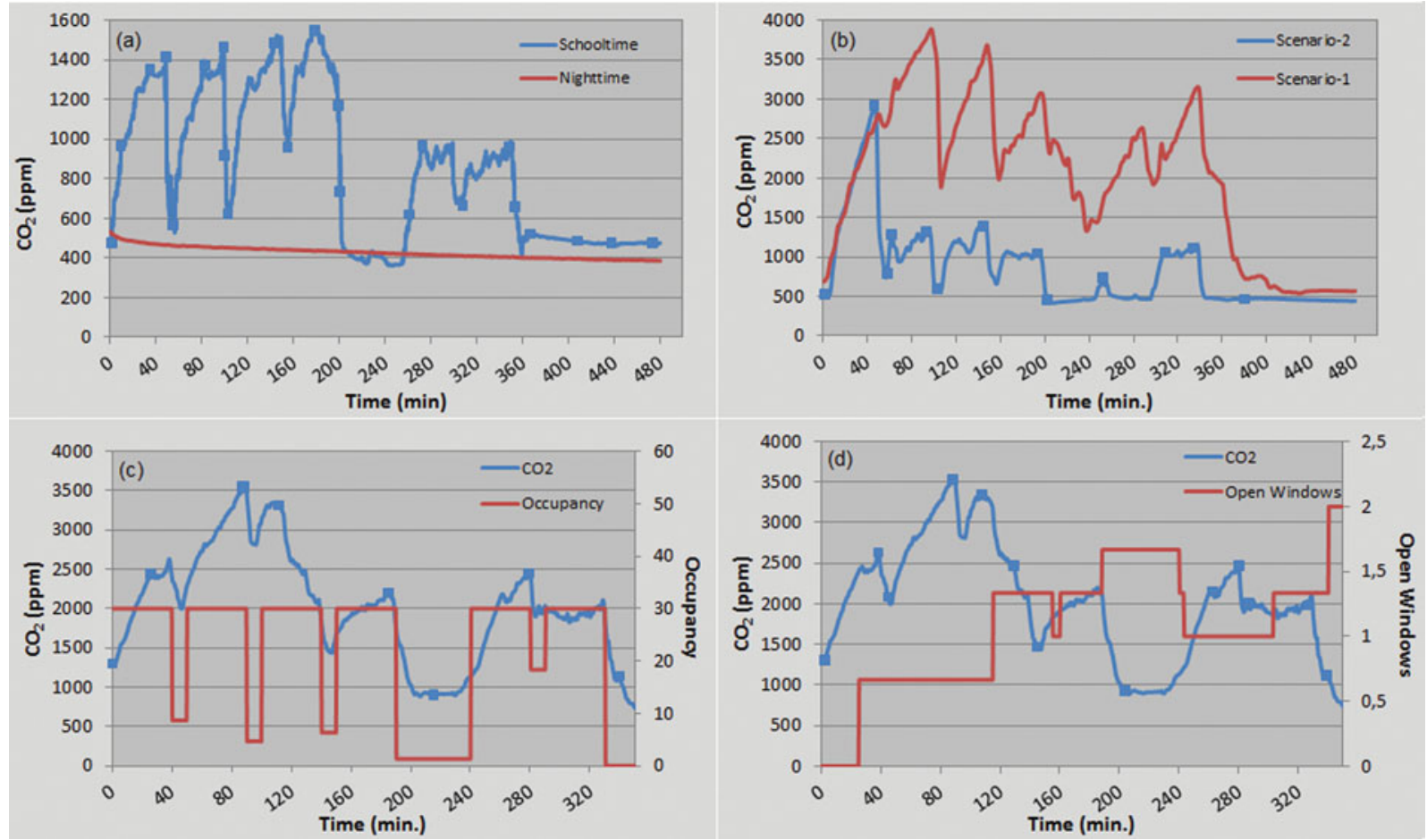

Fig. 5. Average $\mathrm{CO}_{2}$ concentrations in the classroom a. Comparison of daytime and nighttime; b. In scenario 1 and 2; c. In relation to average number of students; and $\mathrm{d}$. In relation to average number of open windows.

than the corresponding weekend concentrations while they were similar for TVOC. The weekday and weekend night-time concentrations, on the other hand, were similar for TVOC (at about $85 \mathrm{ppb}$ ) and $\mathrm{CO}_{2}$ (at about background levels of 350 $\mathrm{ppm}$ ) but the mean weekend-nighttime $\mathrm{PM}_{2.5}$ concentration $\left(30 \mu \mathrm{g} / \mathrm{m}^{3}\right)$ was 9-fold lower than the weekday-schooltime concentration. The above day-night and weekday-weekend comparisons implicate that the main factors that determine $\mathrm{PM}_{2.5}$ and $\mathrm{CO}_{2}$ concentrations are most probably the students and inefficiency of the natural ventilation to reduce the increased concentrations of these two pollutants by the presence of the children (as the emission source by metabolic activity for $\mathrm{CO}_{2}$ and reentrainment of settled dust by movement for $\mathrm{PM}_{2.5}$ ), whereas TVOC concentrations were probably driven by both the other indoor sources and outdoor sources. A time period, such as a night, would be sufficient to bring down $\mathrm{CO}_{2}$ but a longer time, such as a weekend, would be required for $\mathrm{PM}_{2.5}$ concentrations to come back down.

Figure 5 illustrates the efficiency of natural ventilation by comparing $\mathrm{CO}_{2}$ concentrations of schooltime and nighttime, Scenarios 1 and 2, and relating the concentrations to the number of students in the classroom. Figure 5a shows that $\mathrm{CO}_{2}$ concentrations were reduced considerably during breaks, especially in the lunch break to the night-time background levels, while Figure 5b shows that the concentrations can be kept at lower levels by having the children open all the windows and leave the classroom during the breaks (Scenario 2) compared to regular operation (Scenario 1). Figures $5 \mathrm{c}$ and $5 \mathrm{~d}$ show the concentrations along with the number of students in the classroom on two different regular operation days, where windows were mainly open (Figure 5c) and opened only when children felt uncomfortable during the 3rd period (Figure 5d). TVOC levels were also lower in Scenario $2(144 \pm 62 \mathrm{ppb})$ compared to Scenario $1(222 \pm 141$ $\mathrm{ppb}$ ) indicating that indoor sources might be stronger compared to those of outdoors. On the other hand, comparison of $\mathrm{PM}_{2.5}$ concentrations in Scenarios 1 and 2 yielded that they were higher in Scenario $2\left(640 \pm 431 \mu \mathrm{g} / \mathrm{m}^{3}\right)$ with increased natural ventilation compared to regular operation $\left(490 \pm 350 \mu \mathrm{g} / \mathrm{m}^{3}\right)$ probably due to increased transport of PM from outside. The school is located in a part of the city where it is surrounded by industrial establishments including two cement plants and its quarries, two beer plants, a household - personal care product plant, a number of SMEs, and open fields, in addition to the residential areas (see Figure S1 in SI). It is also located within $500 \mathrm{~m}$ of a highway and a junction of major roadways. The current observations hint at major re-entrainment of soil particles from the open fields next to the school especially on windy days. A limitation of this study was that contaminant concentrations could not be measured outdoors, so the ones measured by the municipality of greater İzmir at a close-by station (Bornova, ca. $2 \mathrm{~km}$ north of the school) are provided as a general information. The October 2014-January 2015 monthly average concentration ranges of $\mathrm{PM}_{10}$ and $\mathrm{CO}$ were $37-51$ and $446-821 \mu \mathrm{g} / \mathrm{m}^{3}$ with overall averages of 45 and $628 \mu \mathrm{g} / \mathrm{m}^{3}$, respectively. Average concentrations of February and March 2015 were 35 and $36 \mu \mathrm{g} / \mathrm{m}^{3}$ for $\mathrm{PM}_{10}$ and 243 and $211 \mu \mathrm{g} / \mathrm{m}^{3}$ for $\mathrm{CO}$, respectively.

Figure 5 also illustrates that natural ventilation is generally not sufficient enough to keep $\mathrm{CO}_{2}$ concentrations below $1000 \mathrm{ppm}$ or $1500 \mathrm{ppm}$, the two commonly used thresholds 


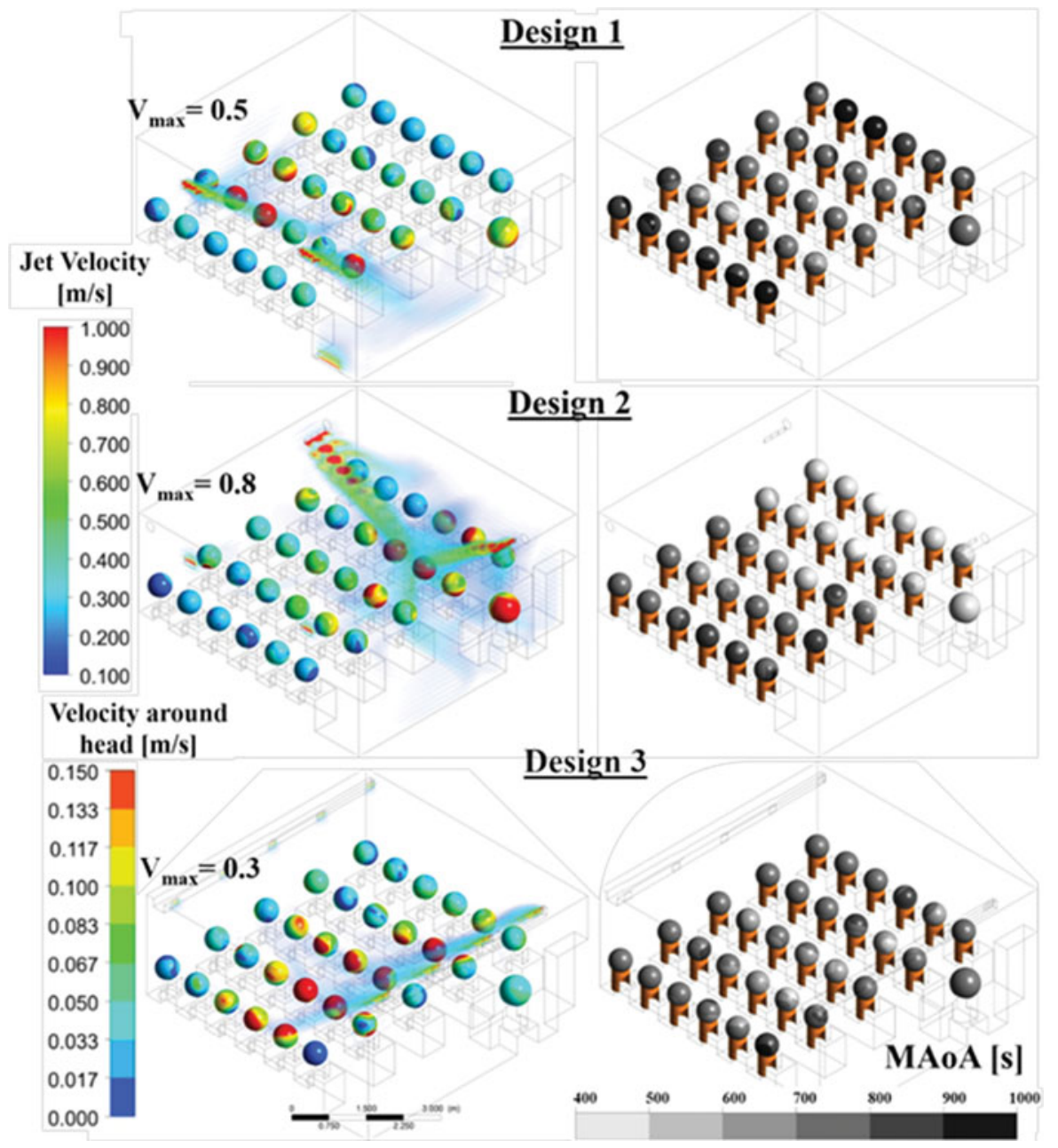

Fig. 6. Comparison of different ventilation designs by means of air velocity and mean age of air (MAoA).

and performance related levels, and unable to keep the concentrations to approach toxicologically relevant levels.

\section{CFD modeling}

Three different designs were compared for their ability to satisfy the desired criteria for the maximum allowed air velocity $(0.15 \mathrm{~m} / \mathrm{s})$ for assuring thermal comfort, occurrence of unventilated or high velocity regions, and MAoA distribution inside the classroom for an airflow rate of $400 \mathrm{~m}^{3} / \mathrm{h}$ and blowing angle of $30^{\circ}$. The best design among the three was selected by this comparison.

The velocity distributions on the spherical air regions defined around the heads for different designs are given in Figure 6. The same color scheme with different scales was used to visualize the jet flow inside the classroom and velocity distribution around the heads. Red heads indicate students subjected to draught, whereas blue heads indicate poorly ventilated students. Green heads represent the students which are under comfortable conditions by means of air velocity. For comparison, the number of students subjected to draught seems higher; however, there is air movement nearly all through the classroom in Design 3. When maximum velocity around heads is also taken into account, it is seen that Design 3 has the lowest value which is the desired condition.

Local MAoA values on the spherical air regions defined around the heads are also given in Figure 6 for different ventilation designs. Students at the middle part of the classroom have more fresh air than the students sitting along the sides of the classroom in Design 1. In Design 2, classroom is divided into two parts where there is more fresh air in the windowside half, while Design 3 has the most homogenous fresh air distribution. The maximum, minimum, and standard deviation values of the average MAoA values for every sphere for different designs are given in Table 2. Design 2 has the lowest average value, whereas Design 1 has the highest. As

Table 2. Mean age of air (MAoA) in different designs.

\begin{tabular}{lccc}
\hline MAoA [s] & Design 1 & Design 2 & Design 3 \\
\hline Maximum & 941 & 812 & 876 \\
Minimum & 623 & 486 & 621 \\
Average & 789 & 655 & 728 \\
Standard deviation & 83 & 105 & 48 \\
\hline
\end{tabular}


the fresh air is directed through the aisles inside the classroom in Design 3, the average MAoA value is higher than that of Design 2. Although Design 2 has better values for maximum and minimum MAoA, standard deviation for Design 3 is lower which indicated that the fresh air distribution is more homogenous. Considering the results of the velocity distribution, Design 3 has been selected as the best design of the three.

The selected design was further investigated to discuss the effect of the blowing angle $\left(30,45,60\right.$, and $\left.75^{\circ}\right)$ and different flow rates $\left(335,400,560\right.$, and $\left.840 \mathrm{~m}^{3} / \mathrm{h}\right)$ on the ventilation effectiveness and the results were presented in a previous study (Karadeniz et al. 2015).

\section{Application of the intervention}

\section{Ventilation}

An HRV unit for each classroom was chosen to provide necessary airflow rates calculated according to criteria defined in Building Bulletin 101 as given in the section " $\mathrm{CO}_{2}$ modeling for determination of ventilation rate." System design (distribution - collection channels, air inlet, and outlet terminals) were designed according to results of the CFD analysis (Design 3) given the previous section (CFD modeling), and applied (Figure S3 in SI).

Ventilation system operates based on demand controlled ventilation. At the beginning of school day, the airflow rate is supplied as the minimum flow rate which provides average $\mathrm{CO}_{2}$ concentration below $1500 \mathrm{ppm}$ during the day in school. Minimum flow rate is calculated for maximum student number and no student leaving class during the breaks. Daily consecutive lecture number is four. During the day, the flow rate is going to be changed proportionally by the controller according to $\mathrm{CO}_{2}$ concentration detected by a sensor. A manual control option is also available for maximum flow rate in case of unexpected emission of pollutants.

\section{$I A Q$}

A 2-week monitoring campaign was conducted after the implementation of mechanical ventilation system. The 2-week averages and maximum concentrations are compared here to assess its effect on IAQ. TVOC concentrations were not reduced after the implementation. However, $\mathrm{CO}_{2}$ and $\mathrm{PM}_{2.5}$ concentrations were lower by $29 \%$ for both of the pollutants when average values are taken into account, and by $68 \%$ for $\mathrm{CO}_{2}$ and $46 \%$ for $\mathrm{PM}_{2.5}$ when the maximums are considered. Rosbach et al. (2013) applied a ventilation intervention to 17 primary schools during the heating seasons (OctoberApril) of 2010-2011 and 2011-2012, in which the mean $\mathrm{CO}_{2}$ level was reduced by $37 \%$. Norbäck et al. (2011) reported a $24 \%$ reduction in the mean $\mathrm{CO}_{2}$ concentration in the schools of mid-Sweden (Enköping) with a modified ventilation system.

The overall schooltime average concentration for $\mathrm{CO}_{2}$ was $1095 \pm 200 \mathrm{ppm}$. Building Bulletin 101 requires that the average $\mathrm{CO}_{2}$ concentration over a period without a long break should not exceed $1500 \mathrm{ppm}$ while the maximum value is required to be below $5000 \mathrm{ppm}$ (BDE 2006). The average concentration of the four periods before lunch break is compared with the $1500 \mathrm{ppm}$ standard value. Before intervention, the standard was violated on two regular operation weeks (Scenario 1) with average concentrations of 2658 and $3919 \mathrm{ppm}$, while it was also violated in one of the two Scenario 2 weeks (1199 and 2985 ppm). The corresponding average concentration after the implementation was $1170 \mathrm{ppm}$ complying with the standard. The maximum concentration during this period was $1680 \mathrm{ppm}$, which is much lower than those measured before the implementation, although they also never exceeded the $5000 \mathrm{ppm}$ level.

Even three of the 6-weekly average TVOC concentrations $(144,175$, and $222 \mathrm{ppb})$ were higher than the stringer (suggested) standard level of $130 \mathrm{ppb}$ but lower than that of (261 ppb) for offices (Ugranli et al., 2015). The average concentration after the implementation was $184 \mathrm{ppb}$ similar to those measured before the implementation. All weekly average concentrations of $\mathrm{PM}_{2.5}$ before the implementation were in exceedance of the American 24-h average ambient air standard concentration (which is applicable to indoor air) of $65 \mu \mathrm{g} / \mathrm{m}^{3}$ (Ugranli et al. 2015). The concentrations after the implementation were reduced (to $295 \pm 217 \mu \mathrm{g} / \mathrm{m}^{3}$ ) but still not below the standard level.

The comparison of before and after intervention is based on measurements performed in different time periods, resulting in confounding by such variables as meteorology, indoor, and outdoor pollutant source strengths, which is a limitation of the study.

\section{Thermal comfort}

After the installation of the mechanical ventilation system, a thermal comfort assessment was made in February using a 2week measurement campaign. Diurnal variation in the mean temperature values in the classroom are shown in Figure 7. Similar to January, the temperature values were always out of the comfort zone, and sometimes much lower than the indicated thermal comfort limit in February. The average RH value was within the $40 \%-50 \%$ range which influence on thermal comfort is rather limited at these temperature and metabolic activity levels as mentioned in ISO 7730 (2005). The available data clearly showed that the capacity of the school's heating system was insufficient to meet the peak load, therefore, unable to increase the temperature in the classroom to the minimum level required for thermal comfort during periods with very low outside temperatures such as in January and February. Considering the outside temperatures were similar, temperature measurements in January, representing before intervention, and in February, representing after intervention, were compared. However, a considerable difference was not observed (see Figures 4 and 7), except for, in contrast to January the temperature in the classroom in February did not drop during breaks when the device was running at the maximum load.

Results of the 3-day surveys performed after intervention in February 2015 are presented in Table 3, during which the outside temperature was quite low. These surveys were performed only in the two classrooms with heat recovery devices installed (the pilot classroom and the neighboring classroom). 


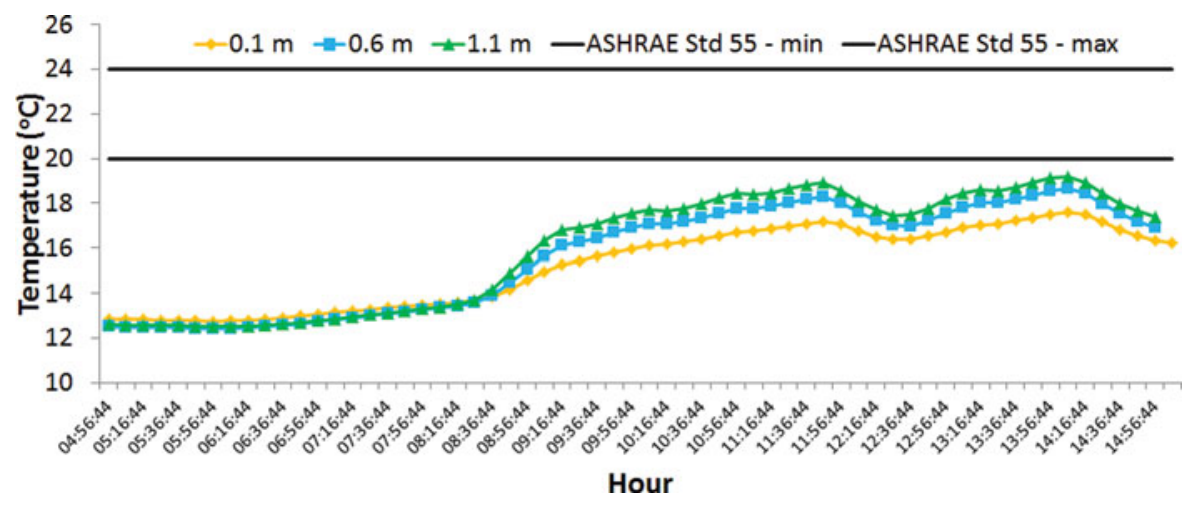

Fig. 7. Diurnal variation in the mean temperature in the pilot classroom in February.

Table 3. Results of February 2015 after intervention thermal comfort survey results.

\begin{tabular}{lccc}
\hline Date/classroom & $\mathrm{T}\left({ }^{\circ} \mathrm{C}\right)$ & $\mathrm{RH}(\%)$ & Mean PMV \\
\hline 11.02.2015/Pilot & 18.0 & 38 & -0.22 \\
11.02.2015/Neighbor & 19.0 & 40 & -0.04 \\
12.02.2015/Pilot & 15.0 & 50 & -0.88 \\
12.02.2015/Neighbor & 14.9 & 42 & -1.46 \\
17.02.2015/Pilot & 14.4 & 37 & -1.88 \\
17.02.2015/Neighbor & 14.6 & 43 & -1.24 \\
Mean & 16.0 & 41.7 & -0.95 \\
Standard deviation & 1.99 & 4.7 & 0.72 \\
Minimum & 14.4 & 37 & -1.88 \\
Maximum & 19.0 & 50 & -0.04 \\
\hline
\end{tabular}

PMV: predicted mean vote.

Indoor temperature and $\mathrm{RH}$ varied from $14.4^{\circ} \mathrm{C}$ to $19^{\circ} \mathrm{C}$ and from $37 \%$ to $50 \%$, with the mean values of $16.0^{\circ} \mathrm{C}$ and $41.67 \%$, respectively. Under these conditions, the PMV value varied between -1.88 and -0.04 , while the average PMV was -0.95 . Both measurements and the PMV values indicated uncomfortable conditions.

Cross-questions resulted in elimination of 80 out of 251 $(31.9 \%)$ participant questionnaires in the first survey administered in December, whereas the rate reduced to 47 out of 285 $(16.5 \%)$ in January, and to 23 out of 168 (13.7\%) in February. The decrease in the elimination rate indicates that students started to assess the thermal environment in a more consistent manner.

\section{Conclusion}

In this study, results of measurement campaigns of IEQ before and after installation of HRV in a primary school located in an urban area are reported, where some industrial plants (such as cement, brewing, chemical), a highway and an intersection of major roadways, residential areas, open fields are found. $\mathrm{A} \mathrm{CO}_{2}$-based modeling was performed to determine the required flow rates that would comply with an international ventilation standard. Then, CFD modeling was performed to determine the design that would provide comfort in terms of air velocity.

Temperature, RH measurements, and subjective assessment using PMV indicated that there were times when thermal comfort was not attained while IAQ measurements showed that $\mathrm{CO}_{2}$, TVOC, and PM concentrations in the pilot classroom reached undesired levels due to both indoor and outdoor sources, showing that they cannot be prevented with natural ventilation by simply opening the windows during lecture hours and/or breaks between lectures in classroom. Natural ventilation is also deterred by the outdoor meteorological conditions, especially in cold winter and hot summer months. Installation of HRV unit resulted in considerable reductions in $\mathrm{CO}_{2}$ and $\mathrm{PM}$ concentrations improving IAQ, whereas thermal comfort was still not attained during quite cold days. Although it was not possible to determine whether the heat recovery device was effective since temperatures remained below the limit required for thermal comfort, it was seen that the temperature in the classroom after intervention did not drop during breaks when the device run at the maximum load, which may suggest that the heat recovery device would not adversely affect thermal comfort.

Velocity distribution with steady MAoA distributions obtained by computer simulations provide a basis for selecting between different designs and effect of different parameters on ventilation effectiveness. The CFD analysis may be extended to other designs, and more parameters $\left(\mathrm{CO}_{2}\right.$ and other contaminants concentration distribution) might be investigated. The proposed way of representing the $3 \mathrm{D}$ data can also be used for calculating the individual flow rates for every occupant, and more specific data can be obtained to determine and define ventilation effectiveness, helping us to find the most efficient way of ventilating a space.

School buildings are deterministically well-defined in function and geometry among others buildings. Most school buildings are built and furnished by government in Turkey by using the same architectural design. Detailed CFD analysis given here is, and the ones to be developed considering sophisticated geometric and thermal models, will be the best tool to have good ventilation effectiveness in classrooms.

This intervention study was a part of the city-wide main project that aimed to increase awareness of the students and their families, teachers, and staff regarding importance of 
IEQ both at school and home due to its possible effects on children's health and academic performance, one of the major challenges of today's societies all around the globe. The scientific activity at the school, and presentation of educational seminars were reported by both the students and teachers/managers to improve their knowledge and perception regarding importance of IEQ.

\section{Acknowledgment}

The authors would like to thank the students, teachers, and the managers of Nihat Gündüz Ortaokulu, especially Ms. Özlem Atik Durkaç and Mr. Osman Alemdar, for their voluntary and enthusiastic participation in the study.

\section{Funding}

The authors would like to express their gratitude to Mechanical Engineering Chamber of İzmir for their substantial support, the HVAC industry (Eneko, Meytes, Tekpa, and Systemair) for the financial support, Dr. Arif H. Cimrin for the IAQ monitor, and Ministry of Education-Izmir Directorate for permission and support for the study.

\section{References}

Banto, J., D. Barrero, M. Reggio, and B. Ozell. 2004. Airflow modelling in a computer room. Building and Environment 39:1393-402.

Annesi-Maesano, I., N. Baiz, S. Banerjee, P. Rudnai, S. Rive, and S. Grp. 2013. Indoor air quality and sources in schools and related health effects. Journal of Toxicology and Environmental Health-Part B-Critical Reviews 16:491-550.

Annesi-Maesano, I., M. Hulin, F. Lavaud, C. Raherison, C. Kopferschmitt, F. de Blay, D. André Charpin, and C. Denis. 2012. Poor air quality in classrooms related to asthma and rhinitis in primary schoolchildren of the French 6 cities study. Thorax 67:682-8.

ASHRAE. 2013. Standard 55-Thermal environmental conditions for human occupancy. Atlanta: ASHRAE.

Babayiğit, M.A., B. Bakır, Ö.M. Tekbaş, R. Oğur, A. Kılıç, and S. Ulus. 2014. Indoor air quality in primary schools in Keçiören, Ankara. Turkish Journal of Medical Sciences 44:137-44.

Bakó-Biró, Z., D.J. Clements-Croome, N. Kochhar, H.B. Awbi, and M.J. Williams. 2012. Ventilation rates in schools and pupils' performance. Building and Environment 48:215-23.

Bartak, M., I. Beausoleil-Morrison, J.A. Clarke, J. Denev, F. Drkal, M. Lain, I.A. Macdonald, A. Melikov, Z. Popiolek, and P. Stankov. 2002. Integrating CFD and building simulation. Building and Environment 37:865-71.

BDE. 2006. Building Bulletin 101, Ventilation of School Buildings: Regulations Standards Design Guidance. British Department for Education.

Chanteloup, V., and P. Mirade. 2009. Computational fluid dynamics (CFD) modelling of local mean age of air distribution in forcedventilation food plants. Journal of Food Engineering 90:90-103.

Daisey, J.M., W.J. Angell, and M.G. Apte. 2003. Indoor air quality, ventilation and health symptoms in schools: An analysis of existing information. Indoor Air 13:53-64.

de Gennaro, G., P.R. Dambruoso, A.D. Loiotile, A. Di Gilio, P. Giungato, M. Tutino, A. Marzocca, A. Mazzone, J. Palmisani, and F. Porcelli. 2014. Indoor air quality in schools. Environmental Chemistry Letters 12:467-82.
Demirel, G., O. Özden, T. Döğeroğlu, and O.F. Gaga. 2014. Personal exposure of primary school children to BTEX, NO2 and ozone in Eskişehir, Turkey: Relationship with indoor/outdoor concentrations and risk assessment. Science of the Total Environment 473-4, $537-48$.

Ekmekcioglu, D., and S.S. Keskin. 2007. Characterization of indoor air particulate matter in selected elementary schools in Istanbul, Turkey. Indoor and Built Environment 16:169-76.

Elbayoumi, M., N.A. Ramli, N.F.F. Md Yusof, and W. Al Madhoun. 2013. Spatial and seasonal variation of particulate matter (PM10 and PM2.5) in Middle Eastern classrooms. Atmospheric Environment 80:389-97.

Faustman, E.M., S.M. Silbernagel, R.A. Fenske, T.M. Burbacher, and R.A. Ponce. 2000. Mechanisms underlying children's susceptibility to environmental toxicants. Environmental Health Perspectives 108:13-21.

Fuoco, F., L. Stabile, G. Buonanno, C. Trassiera, A. Massimo, A. Russi, M. Mazaheri, L. Morawska, and A. Andrade. 2015. Indoor air quality in naturally ventilated italian classrooms. Atmosphere 6:1652-75.

Gan, G. 2000. Effective depth of fresh air distribution in rooms with single-sided natural ventilation. Energy and Buildings 31:65-73.

Halek, F., M. Kianpour-Pad, and A. Kavousirahim. 2013. Parametric evaluation of indoor particulate matters in elementary schools in the Central of Tehran. Indoor and Built Environment 22:580-5.

Haverinen-Shaughnessy, U., R.J. Shaughnessy, E.C. Cole, O. Toyinbo, and D.J. Moschandreas. 2015. An assessment of indoor environmental quality in schools and its association with health and performance. Building and Environment 93(Part 1):35-40.

Hu, S.C., and Y.K. Chuah. 2003. Deterministic simulation and assessment of airrecirculation performance of unidirectional-flow cleanrooms that incorporate age of air concept. Building and Environment 38:563-70.

Ianniella, E. 2011. Ventilation systems and IAQ in school buildings. REHVA Journal March:26-9.

ISO. 2005. ISO 7730 Ergonomics of the thermal environmentAnalytical determination and interpratation of thermal comfort using calculation of the PMV and PPD indices and local thermal comfort criteria. Geneva, Switzerland: International Standards Organization.

Jovanović, M., B. Vučićević, V. Turanjanin, M. Živković, and V. Spasojević. 2014. Investigation of indoor and outdoor air quality of the classrooms at a school in Serbia. Energy 77:42-8.

Kalema, T., and M. Viot. 2014. Methods to reduce the $\mathrm{CO}(2)$ concentration of educational buildings utilizing internal ventilation by transferred air. Indoor Air 24:71-80.

Karadeniz, Z.H., G. Gacaner, O. Ekren, S. Aktakka, S.C. Sofuoglu, and A.M. Toksoy. 2015. Investigation of different ventilation scenarios for a classroom. 8th Mediterranean Congress of HVAC, CLIMAMED, Juan-les Pins, France, September 10-11.

Kosonen, R., and P. Mustokallio. 2015. Air distribution in a classroom. REHVA Journal October:14-6.

Lee, S.C., and M. Chang. 2000. Indoor and outdoor air quality investigation at schools in Hong Kong. Chemosphere 41:109-13.

Mainka, A., E. Bragoszewska, B. Kozielska, J.S. Pastuszka, and E. Zajusz-Zubek. 2015. Indoor air quality in urban nursery schools in Gliwice, Poland: Analysis of the case study. Atmospheric Pollution Research 6:1098-104.

Mendell, M.J., and G.A. Heath. 2005. Do indoor pollutants and thermal conditions in schools influence student performance? A critical review of the literature. Indoor Air 15:27-52.

Mentese, S., A.Y. Rad, M. Arısoy, and G. Güllü. 2012. Multiple comparisons of organic, microbial, and fine particulate pollutants in typical indoor environments: Diurnal and seasonal variations. Journal of the Air and Waste Management Association 62:1380-93.

Mizuno, T., and M. Warfield. 1992. Development of three-dimensional thermal airflow analysis computer program and verification test. ASHRAE Transactions 98:329-38. 
Mohamad, N., M.T. Latif, and M.F. Khan. 2016. Source apportionment and health risk assessment of PM10 in a naturally ventilated school in a tropical environment. Ecotoxicology and Environmental Safety 124:351-62.

Murakami, S., 1997. Flow and temperature fields around human body with various room air distribution, CFD study on computational thermal manikin (Part 1). ASHRAE Transactions 103:3-15.

Murakami, S., S. Kato, and J. Zeng. 1998. Flow and temperature fields around human body with various room air distribution, CFD study on computational thermal manikin (Part 2). ASHRAE Transactions 104:234-66.

Murakami, S., S. Kato, and J. Zeng. 2000. Combined simulation of airflow, radiation and moisture transport for heat release from a human body. Building and Environment 35:489-500.

Norbäck, D., G. Wieslander, X. Zhang, and Z. Zhao. 2011. Respiratory symptoms, perceived air quality and physiological signs in elementary school pupils in relation to displacement and mixing ventilation system: an intervention study. Indoor Air 21:427-37.

Rosbach, J.T., M. Vonk, F. Duijm, J.T. Van Ginkel, U. Gehring, and B. Brunekreef. 2013. A ventilation intervention study in classrooms to improve indoor air quality: The FRESH study. Environmental Health 12:110.

Satish, U., M.J. Mendell, K. Shekhar, T. Hotchi, D. Sullivan, S. Streufert, and W.J. Fisk. 2012. Is CO2 an indoor pollutant? Direct effects of low-to-moderate $\mathrm{CO} 2$ concentrations on human decision-making performance. Environmental Health Perspectives 120:1671-7.

Shaughnessy, R.J., U. Haverinen-Shaughnessy, A. Nevalainen, and D. Moschandreas. 2006. A preliminary study on the association between ventilation rates in classrooms and student performance. Indoor Air 16:465-8.

Shendell, D.G., R. Prill, W.J. Fisk, M.G. Apte, D. Blake, and D. Faulkner. 2004. Associations between classroom $\mathrm{CO}_{2}$ concentrations and student attendance in Washington and Idaho. Indoor Air $14: 333-41$

Sofuoglu, A., N. Kiymet, P. Kavcar, and S.C. Sofuoglu. 2010. Polycyclic and nitro musks in indoor air: A primary school classroom and a women's sport center. Indoor Air 20:515-22.

Sofuoglu, S.C., G. Aslan, F. Inal, and A. Sofuoglu. 2011. An assessment of indoor air concentrations and health risks of volatile organic compounds in three primary schools. International Journal of Hygiene and Environmental Health 214:38-46.
Sohn, J., W. Yang, J. Kim, B. Son, and J. Park. 2009. Indoor air quality investigation according to age of the school buildings in Korea. Journal of Environmental Management 90:348-54.

Stabile, L., M. Dell'Isola, A. Frattolillo, A. Massimo, and A. Russi. 2016. Effect of natural ventilation and manual airing on indoor air quality in naturally ventilated Italian classrooms. Building and Environment 98:180-9.

Stafford, T.M. 2015. Indoor air quality and academic performance. Journal of Environmental Economics and Management 70:34-50.

Teli, D., M.F. Jentsch, P.A.B. James, and A.S. Bahaj. 2012. Field study on thermal comfort in a UK primary school. 7th Windsor Conference: The chancing context of comfort in an unpredictable world, London, UK, April 12-15.

Twardella, D., W. Matzen, T. Lahrz, R. Burghardt, H. Spegel, L. Hendrowarsito, A.C. Frenzel, and H. Fromme. 2012. Effect of classroom air quality on students' concentration: Results of a cluster-randomized cross-over experimental study. Indoor Air $22: 378-87$

Ugranli, T., M. Toprak, G. Gursoy, A.H. Cimrin, and S.C. Sofuoglu. 2015. Indoor environmental quality in chemistry and chemical engineering laboratories at Izmir Institute of Technology. Atmospheric Pollution Research 6:147-53.

Wang, Y., J. Kuckelkorn, F. Zhao, L. Mu, and H. Spliethoff. 2014a. Indoor air environment and heat recovery ventilation in a passive school building: A case study for winter condition. $A S H R A E$ Transactions 120:TT1-TT8.

Wang, Y., F.-Y. Zhao, J. Kuckelkorn, D. Liu, L.Q. Liu, and X.-C. Pan. 2014b. Cooling energy efficiency and classroom air environment of a school building operated by the heat recovery air conditioning unit. Energy 64:991-1001.

Wargocki, P., and N.A.F. Da Silva. 2015. Use of visual $\mathrm{CO}_{2}$ feedback as a retrofit solution for improving classroom air quality. Indoor Air 25:105-14.

Wargocki, P., J. Sundell, W. Bischof, G. Brundrett, P.O. Fanger, F. Gyntelberg, S.O. Hanssen, P. Harrison, A. Pickering, O. Seppanen, and P. Wouters. 2002. Ventilation and health in non-industrial indoor environments: Report from a European Multidisciplinary Scientific Consensus Meeting (EUROVEN). Indoor Air 12:113-28.

Yang, W., J. Sohn, J. Kim, B. Son, and J. Park. 2009. Indoor air quality investigation according to age of the school buildings in Korea. Journal of Environmental Management 90:348-54. 